
\title{
Implementasi Manajemen Bandwidth VoIP pada IP- PBX Menggunakan Routerboard di Jaringan Intranet
}

\author{
Nadhirotun Maulidiyah', Martono Dwi Atmadja ${ }^{2}$, M. Abdullah Anshori ${ }^{3}$ \\ 1,2,3 Program Studi Jaringan Telekomunikasi Digital, \\ Jurusan Teknik Elektro, Politeknik Negeri Malang, Indonesia \\ 1nadhiramld33@gmail.com, ${ }^{2}$ martono.dwi@,polinema.ac.id, ${ }^{3}$ moh.abdullah@polinema.ac.id
}

\begin{abstract}
The growing number of internet applications and their users can affect the quality of the internet, each application has different traffic needs. In addition, bandwidth management can also lend bandwidth that has been allocated in accordance with its priorities in order to optimize existing bandwidth usage. Regulating and limiting internet bandwidth usage is indeed an important thing when our internet connection is limited. We need to limit the bandwidth quota of each user connected to the Mikrotik Router. In Mikrotik Router itself, there are features that can limit bandwidth, namely simple queue and queue tree. In the use of VoIP services, bandwidth management is required to manage traffic on the network, the appropriate bandwidth settings can optimize the speed of data transmission. Looking at the internet needs, this research designs an implementation of bandwidth management using routerboard, which will be applied to IP-PBX and use raspberry pi as a server. The results of the research on bandwidth management implementation in simple queue and queue tree is each able to serve 6 users with PCMU codecs, from the test obtained packet loss value of $0.00 \%$ from 3 clients, and jitter has an average value of $167.37 \%$ from 3 clients.
\end{abstract}

Keywords: Bandwidth, VoIP, Raspberry Pi, Codec PCMU, QoS.

Abstrak - Semakin berkembangnya aplikasi internet dan penggunanya yang semakin banyak dapat mempengaruhi kualitas jaringan internet, setiap aplikasi internet memiliki kebutuhan trafik yang berbeda-beda. Selain itu, manajemen bandwidth juga dapat meminjamkan bandwidth yang telah dialokasikan sesuai dengan prioritasnya agar dapat mengoptimalkan penggunaan bandwidth yang ada. Mengatur dan membatasi pemakaian Bandwidth internet memang suatu hal yang penting ketika koneksi internet kita terbatas. Kita perlu membatasi kuota bandwidth tiap user yang terkoneksi ke Router Mikrotik. Pada Router Mikrotik sendiri sudah tersedia fitur yang bisa membatasi (limit) bandwidth yaitu simple queue dan queue tree. Dalam penggunaan layanan voip diperlukan adanya manajemen bandwidth yang berfungsi untuk mengatur trafik pada jaringan, pengaturan bandwidth yang sesuai dapat mengoptimalkan kecepatan pengiriman data. Melihat kebutuhan internet tersebut maka dalam penelitian ini akan dirancang suatu implementasi manajemen bandwidth dengan menggunakan routerboard, yang akan diterapkan pada IP-PBX dan menggunakan raspberry pi sebagai server. Hasil penelitian implementasi manajemen bandwidth pada simple queue dan queue tree tersebut masingmasing mampu melayani 6 pengguna dengan codec PCMU, dari pengujian tersebut didapatkan nilai packet loss sebesar $0.00 \%$ dari 3 client, dan jitter memiliki nilai rata-rata $167,37 \%$ dari 3 client.

Kata kunci : Bandwidth, VoIP, Raspberry Pi, Codec PCMU, QoS.

\section{PEndahuluan}

Mikrotik routerboard adalah suatu hardware yang dapat menjalankan router network tanpa perlu di install ke sebuah PC, karena mikrotik ini telah di desain untuk menjalankan routerOS sehingga dapat menjadi router yang handal untuk penggunanya. Routerboard ini mudah digunakan karena tidak perlu menginstall OS.

Mengatur dan membatasi pemakaian Bandwidth internet memang suatu hal yang penting ketika koneksi internet kita terbatas, misalnya kuota bandwidth yang terbatas dari ISP. Kita perlu membatasi kuota bandwidth tiap user yang terkoneksi ke Router Mikrotik. Pada Router Mikrotik sendiri sudah tersedia fitur yang bisa membatasi (limit) bandwidth yaitu Queue[1].

Dalam penggunaan layanan voip diperlukan adanya manajemen bandwidth yang berfungsi untuk mengatur trafik pada jaringan. Pengaturan bandwidth yang sesuai dapat mengoptimalkan kecepatan pengiriman data.
Dari uraian diatas maka dalam penelitian ini dilakukan implementasi manajemen bandwidth voip pada server single board computer pada IP-PBX menggunakan routerboard di jaringan intranet.

\section{A. Mikrotik}

Mikrotik adalah sebuah perusahaan yang bergerak dibidang produksi hardware dan software yang berhubungan dengan system jaringan komputer yang berkantor pusat di Latvia. Mikrotik didirikan pada tahun 1995 untuk mengembangkan router dan system ISP (Internet Service Protocol) nirkabel.

Mikrotik dibuat oleh MikroTikls sebuah perusahaan di Latvia. Mikrotik awalnya ditujukan untuk perusahaan jasa layanan internet (PJI) atau Internet Service Provider (ISP) yang melayani pelanggannya menggunakan teknologi nirkabel atau wireless. Saat ini MikroTikls memberikan layanan kepada banyak ISP nirkabel untuk layanan akses internet dibanyak negara di dunia dan juga sangat populer di Indonesia. Mikrotik sekarang menyediakan hardware dan software untuk konektivitas internet di sebagian besar 
negara di seluruh dunia. Produk hardware unggulan mikrotik berupa router, switch, antena, dan perangkat produk lainnya. Sedangkan produk software unggulan mikrotik adalah Mikrotik RouterOS.

\section{B. Mangle}

Mangle pada mikrotik merupakan suatu cara untuk menandai paket data dan koneksi tertentu yang dapat diterapkan pada fitur mikrotik lainnya, sepeti pada routes, pemisahan bandwidth pada queues, NAT dan filter rules. Tanda mangle yang ada pada router mikrotik hanya bisa digunakan pada router itu sendiri. Dan yang perlu diingat bahwa proses pembacaan rule mangle ini dilakukan dari urutan pertama ke bawah.

\section{Voice over Internet Protocol (VoIP)}

Voice over Internet Protocol adalah Teknologi yang menjadikan media internet untuk bisa melakukan komunikasi suara jarak jauh secara langsung. Sinyal suara analog, seperti yang anda dengar ketika berkomunikasi di telepon diubah menjadi data digital dan dikirimkan melalui jaringan berupa paket-paket data secara real time. Dalam komunikasi VoIP, pemakai melakukan hubungan telepon melalui terminal yang berupa $\mathrm{PC}$ atau telepon biasa. Dengan bertelepon menggunakan VoIP, banyak keuntungan yang dapat diambil diantaranya adalah dari segi biaya jelas lebih murah dari tarif telepon tradisional, karena jaringan IP bersifat global. Sehingga untuk hubungan Internasionaldapat ditekan hingga $70 \%$. Selain itu, biaya maintenance dapat di tekan karena voicedan data networkterpisah, sehingga IP Phone dapat di tambah, dipindah dan di ubah. Hal ini karena VoIP dapat dipasang di sembarang ethernet dan IP address, tidak seperti telepon konvensional yang harus mempunyai port tersendiri di Sentral atau PBX (Private branch exchange) [2].

\section{Intranet}

Intranet adalah jaringan komputer private atau LAN yang menggunakan IP private dan protocol TCP/IP sebagai protocol standar komunikasi antar komputer.Secara default jaringan intranet tidak bisa mengakses internet dan diperlukan IP public dan perangkat NAT untuk memberi akses internet ke komputer dalam jaringan intranet. Tidak seperti internet yang cakupan nya luas sehingga komputer yang ada di jaringan internet akan bisa diakses oleh siapapun di internet, jaringan intranet dibuat dengan tujuan sebaliknya.

\section{E. Manajemen Bandwidth}

Management Bandwith, adalah suatu alat yang dapat digunakan untuk management dan mengoptimalkan berbagai jenis jaringan dengan menerapkan layanan Quality of Service (QoS) untuk menetapkan tipe-tipe lalulintas jaringan. sedangkan QoS adalah kemampuan untuk menggambarkan suatu tingkatan pencapaian didalam suatu sistem komunikasi data.

Manajemen Bandwidth adalah pengalokasian yang tepat dari suatu bandwidth untuk mendukung kebutuhan atau keperluan aplikasi atau suatu layanan jaringan [3]. Pengalokasian bandwidth yang tepat dapat menjadi salah satu metode dalam memberikan jaminan kualitas suatu layanan jaringan QoS (Quality Of Services).

Manajemen Bandwidth adalah proses mengukur dan mengontrol komunikasi (lalu lintas, paket) pada link jaringan, untuk menghindari mengisi link untuk kapasitas atau overfilling link, yang akan mengakibatkan kemacetan jaringan dan kinerja yang buruk [4].

Maksud dari manajemen bandwidth ini adalah bagaimana kita menerapkan pengalokasian atau pengaturan bandwidth dengan menggunakan sebuah PC Router Mikrotik. Manajemen bandwith memberikan kemampuan untuk mengatur Bandwidth jaringan dan memberikan level layanan sesuai dengan kebutuhan dan prioritas sesuai dengan permintaan pelanggan.

\section{F. FreePBX}

FreePBX merupakan distro open source berbasis web GUI (graphical user interface) [5] yang mampu mengontrol dan mengelola Asterisk (PBX), yang merupakan server komunikasi open source. FreePBX dilisensikan di bawah GNU General Public License (GPL), berlisensi open source. FreePBX dapat diinstall secara manual. Distro FreePBX mencakup sistem OS, Asterisk, FreePBX GUI dan berbagai macam dependensi. FreePbx termasuk dalam distribusi open source seperti the Official FreePBX Distro, AsteriskNOW, Elastix dan RasPBX.

\section{G. IP PBX}

IPPBX adalah Private Branch Exchange (PBX) yang memanfaatkan Internet Protocol, dalam membentuk komunikasi telepon. IP PBX dibangun sebagai konsep jaringan komunikasi generasi masa depan, sebab ia mampu memadukan antar jaringan, seperti jaringan PSTN (jaringan telepon tetap dengan memanfaatkan kabel), jaringan telepon bergerak (GSM/CDMA), jaringan telepon satelit, jaringan Cordless (DECT), dan jaringan telepon berbasis paket Internet Protocol/ATM. Dengan konsep tersebut, IP PBX dapat mengendalikan hubungan telepon secara penuh. Pengendalian dilakukan, melalui perangkat-perangkat IP Telephony, yakni VoIP Gateway, Access Gateway, dan Trunk Gateway[6]. Karena keunggulan yang dimilikinya, perangkat ini menjadi induk dari kinerja dasar VoIP, dalam melakukan transmisi suara dan data. Kehadiran IP PBX telah memberikan kontribusi yang baik pada dunia telekomunikasi. Dengan menggunakan perangkat ini, komunikasi dapat dijalankan dengan lebih efektif dan efisien. Hal ini karena, jumlah line yang digunakan IP PBX, tidak menyesuaikan dengan jumlah telepon yang terpasang, seperti yang diterapkan dalam jaringan PSTN. Oleh karena itu, pemasangan IP PBX dapat menghemat biaya pengeluaran, pembangunan, serta perawatan jaringan (Edvian, 2010).

\section{H. Softphone Linphone}

Linphone adalah suara bebas melalui softphone IP, klien dan layanan SIP . Ini dapat digunakan untuk panggilan dan 
Jurnal Jaringan Telekomunikasi (Jurnal Jartel) E-ISSN:2654-6531 P-ISSN: 2407-0807 Vol. 10, No.4 (2020) 185-190

panggilan langsung audio dan video melalui softswitch VoIP atau IP-PBX. Linphone juga menyediakan kemungkinan untuk bertukar pesan instan [7].

\section{QoS (Quality of Service)}

QoS adalah kemampuan suatu jaringan untuk menyediakan layanan yang baik dengan menyediakan bandwidth, mangatas jitter, dan delay. QoS mengacu pada kemampuan jaringan untuk menyediakan layanan yang lebih baik pada trafik jaringan tertentu melalui teknologi yang berbeda-beda. Tujuan dari QoS adalah untuk memenuhi kebutuhan layanan yang berbeda, yang menggunakan infrastruktur yang sama. Pada QoS terdapat beberapa parameter yaitu delay, packet loss, troughput dan jitter. Terdapat beberapa faktor yang dapat menurunkan nilai QoS seperti : redaman, distorsi, dan noise. [9]

\section{METODE}

\section{A. Rancangan Sistem}

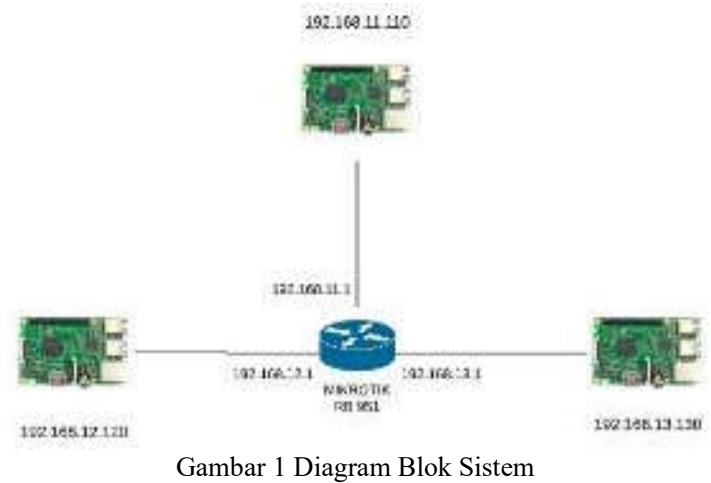

Blok diagram rancangan sistem yang ditunjukkan pada gambar 1. Alur yang dilakukan selama penelitian, yaitu perangkat mikrotik dengan menggunakan raspberry pi sebagai server. Pada sisi client digunakan perangkat smartphone yang sudah terkonfigurasi linphone, setelah itu dibagi menjadi dua dimana 3 pasang di setiap server.

Pada gambar 2 menunjukkan settingan untuk memblokir data selain UDP, pada chain menggunakan forward. Lalu Src.Address diisi IP 0.0.0.0/0 dan Protocol menggunakan UDP dan diberi tanda [!] yang berarti kecuali 17(udp) tersebut.

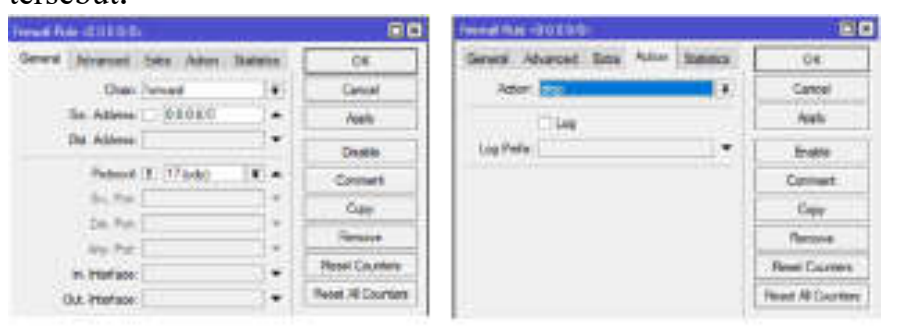

Gambar 2 Settingan untuk memblokir selain UDP

\section{B. Setting Mangel}

Pada gambar 3 menunjukkan settingan mangle untuk menandai agar bisa membuat queue tree, dengan chain prerouting, protocol 17 (udp), In interface ether 2, action menggunakan mark packet, dan packet mark 11.2.iax2in. Lalu klik apply, dan OK.

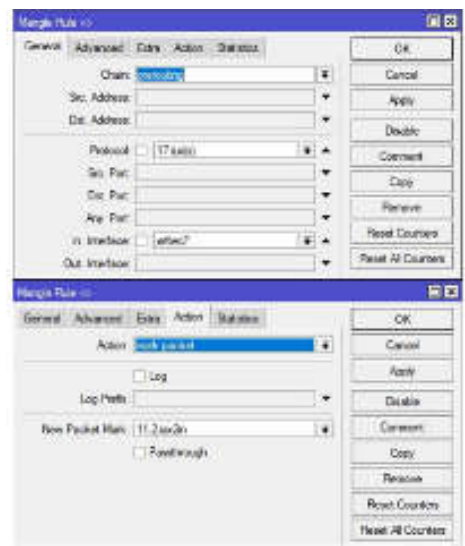

Gambar 3 Packet Mark 11.2in
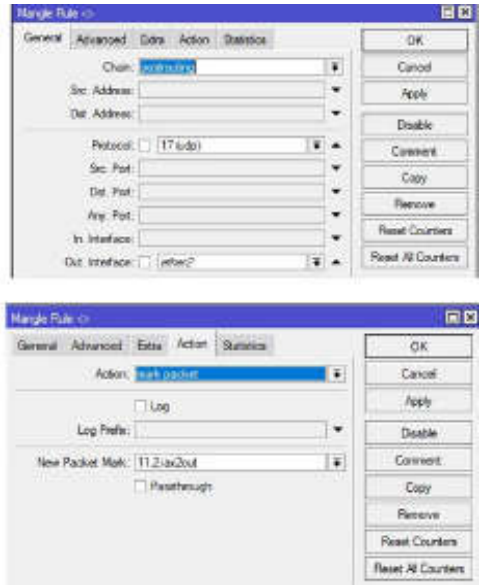

Gambar 4. Packet mark 11.2 out

Pada gambar 4 menunjukkan settingan mangle untuk menandai agar bisa membuat queue tree, dengan chain postrouting, protocol 17 (udp), out interface ether 2, action menggunakan mark packet, dan packet mark 11.2.iax2out. Lalu klik apply, dan OK. 

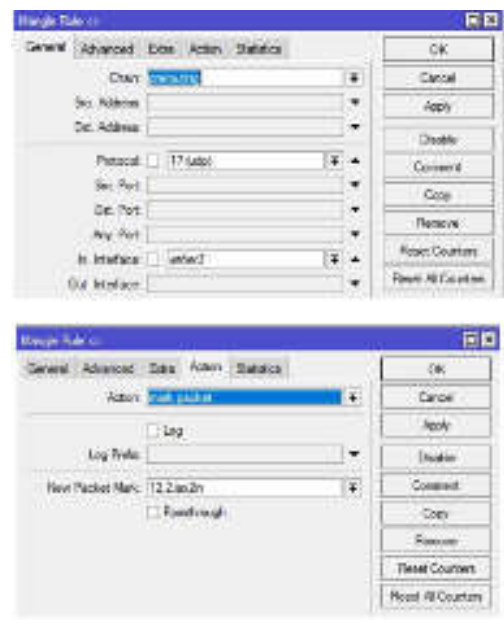

Gambar 5 Packet mark 12.2 in

Pada gambar 5 menunjukkan settingan mangle untuk menandai agar bisa membuat queue tree, dengan chain prerouting, protocol 17 (udp), In interface ether 3, action menggunakan mark packet, dan packet mark 12.2.iax2in. Lalu klik apply, dan OK.

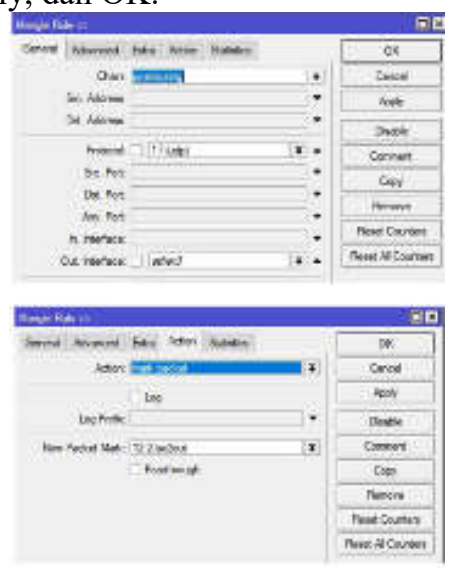

Gambar 6 Packet mark 12.2 out

Pada gambar 6 menunjukkan settingan mangle untuk menandai agar bisa membuat queue tree, dengan chain postrouting, protocol 17 (udp), Out interface ether 3, action menggunakan mark packet, dan packet mark 12.2.iax2out. Lalu klik apply, dan OK.
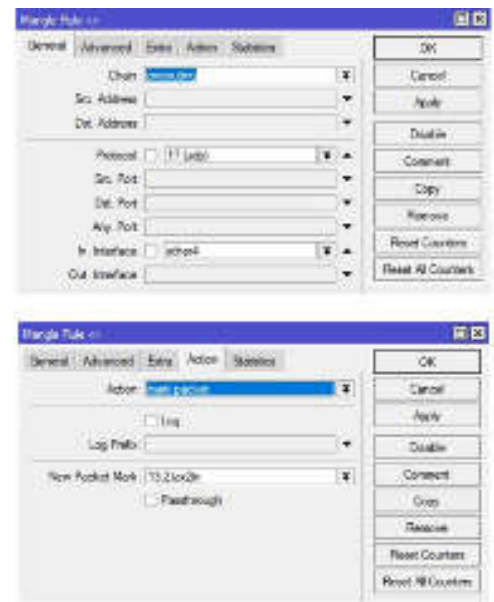

Gambar 7. Packet mark 13.2 in

Pada gambar 7 menunjukkan settingan mangle untuk menandai agar bisa membuat queue tree, dengan chain prerouting, protocol 17 (udp), In interface ether 4, action menggunakan mark packet, dan packet mark 13.2.iax2in. Lalu klik apply, dan OK.

Pada gambar 8 menunjukkan settingan mangle untuk menandai agar bisa membuat queue tree, dengan chain postrouting, protocol 17 (udp), Out interface ether 4, action menggunakan mark packet, dan packet mark 13.2.iax2out. Lalu klik apply, dan OK.
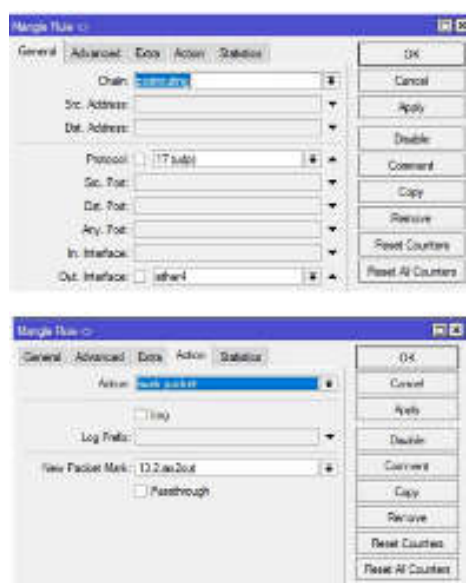

Gambar 8 Packet mark 13.2 out

\section{HASIL DAN PEMBAHASAN}

\section{A. Hasil Pengujian Simple queue}

TABEL I

HASIL DATA DARI MELAKUKAN PANGGILAN MENGGUNAKAN SIMPLE QUEUE DENGAN 1 PASANG

\begin{tabular}{ccccc}
\hline \multirow{2}{*}{$\begin{array}{c}\text { Max } \\
\text { limit } \\
\text { pada } \\
\text { Mikrotik }\end{array}$} & \multicolumn{3}{c}{$\begin{array}{c}\text { Call statistik di softphone pada } \\
\text { pengujian 1 pasang }\end{array}$} & Keterangan \\
\cline { 2 - 5 } & $\begin{array}{c}\text { Bandwidth } \\
(\mathrm{kbps})\end{array}$ & $\begin{array}{c}\text { Jitter } \\
(\mathrm{ms})\end{array}$ & $\begin{array}{c}\text { Packet } \\
\text { loss } \\
(\%)\end{array}$ & \\
\hline 64k & 128 & 287,79 & 0 & $\begin{array}{c}\text { Panggilan putus } \\
\text { putus suara tidak } \\
\text { jelas, } \\
\text { dikarenakan jitter }\end{array}$ \\
\hline
\end{tabular}


Jurnal Jaringan Telekomunikasi (Jurnal Jartel) E-ISSN:2654-6531 P- ISSN: 2407-0807 Vol. 10, No.4 (2020) 185-190

\begin{tabular}{|c|c|c|c|c|}
\hline \multirow{2}{*}{$\begin{array}{c}\text { Max } \\
\text { limit } \\
\text { pada } \\
\text { Mikrotik } \\
\end{array}$} & \multicolumn{3}{|c|}{$\begin{array}{l}\text { Call statistik di softphone pada } \\
\text { pengujian } 3 \text { pasang }\end{array}$} & \multirow[t]{2}{*}{ Keterangan } \\
\hline & $\begin{array}{l}\text { Bandwidth } \\
\text { (kbps) }\end{array}$ & $\begin{array}{l}\text { Jitter } \\
(\mathrm{ms})\end{array}$ & $\begin{array}{l}\text { Packet } \\
\text { loss }(\%)\end{array}$ & \\
\hline $64 \mathrm{k}$ & 193,2 & 305,6 & 0 & $\begin{array}{l}\text { Panggilan putus, } \\
\text { dikarenakan jitter } \\
\text { yang besar }\end{array}$ \\
\hline $128 \mathrm{k}$ & 382,5 & 287,79 & 0 & $\begin{array}{c}\text { Panggilan putus } \\
\text { dikarenakan jitter } \\
\text { yang besar }\end{array}$ \\
\hline $256 \mathrm{k}$ & 477,8 & 83,20 & 0 & $\begin{array}{c}\text { Panggilan tidak } \\
\text { terputus tetapi } \\
\text { delay }\end{array}$ \\
\hline $384 \mathrm{k}$ & 480 & 45,37 & 0 & $\begin{array}{c}\text { Panggilan delay } \\
\text { tetapi tidak seperti } \\
\text { pada max limit } \\
256 \mathrm{k}\end{array}$ \\
\hline $512 \mathrm{k}$ & 483,5 & 12,3 & 0 & Panggilan lancar \\
\hline $\begin{array}{c}\text { rata - } \\
\text { rata }\end{array}$ & 403,4 & 146,84 & 0,00 & \\
\hline & & & & $\begin{array}{l}\text { besar dan tidak } \\
\text { ada packet loss }\end{array}$ \\
\hline $128 \mathrm{k}$ & 160,2 & 90,20 & 0 & $\begin{array}{c}\text { Panggilan ada } \\
\text { delay tetapi } \\
\text { jitternya tidak } \\
\text { sebesar max limit } \\
64 \mathrm{k}\end{array}$ \\
\hline $256 \mathrm{k}$ & 161,9 & 20,6 & 0 & Panggilan lancar \\
\hline $384 \mathrm{k}$ & 158,7 & 15,5 & 0 & Panggilan lancer \\
\hline $512 \mathrm{k}$ & 162 & 2,21 & 0 & Panggilan lancar \\
\hline rata -rata & 154,16 & 83,26 & 0,00 & \\
\hline
\end{tabular}

Pada Tabel 1 menunjukkan hasil data dari melakukan panggilan menggunakan simple queue dengan 1 pasang, nilai tertinggi dari bandwidth adalah $162 \mathrm{kbps}$ pada max limit $512 \mathrm{k}$ dan terendah $128 \mathrm{kbps}$ pada max limit $64 \mathrm{k}$, nilai tertinggi jitter adalah $287,79 \mathrm{~ms}$ pada max limit $64 \mathrm{k}$ dan terendah $2,21 \mathrm{~ms}$ pada max limit $512 \mathrm{k}$.

TABEL II

HASIL DATA DARI MELAKUKAN PANGGILAN MENGGUNAKAN SIMPLE QUEUE DENGAN 2 PASANG.

\begin{tabular}{|c|c|c|c|c|}
\hline \multirow{2}{*}{$\begin{array}{c}\text { Max } \\
\text { limit } \\
\text { pada } \\
\text { Mikrotik }\end{array}$} & \multicolumn{3}{|c|}{$\begin{array}{l}\text { Call statistik di softphone pada } \\
\text { pengujian } 2 \text { pasang }\end{array}$} & \multirow[t]{2}{*}{ Keterangan } \\
\hline & $\begin{array}{c}\text { Bandwidth } \\
\text { (kbps) }\end{array}$ & $\begin{array}{l}\text { Jitter } \\
(\mathrm{ms}) \\
\end{array}$ & $\begin{array}{l}\text { Packet } \\
\text { loss (\%) }\end{array}$ & \\
\hline $64 \mathrm{k}$ & 180 & 278,79 & 0 & $\begin{array}{c}\text { Panggilan putus, } \\
\text { dikarenakan } \\
\text { bandwidth yang } \\
\text { terlalu kecil. } \\
\end{array}$ \\
\hline $128 \mathrm{k}$ & 282,1 & 172,6 & 0 & $\begin{array}{c}\text { Panggilan pada } 1 \\
\text { pasang putus, dan } \\
1 \text { pasangnya lagi } \\
\text { delay } \\
\end{array}$ \\
\hline $256 \mathrm{k}$ & 317,2 & 94,03 & 0 & $\begin{array}{c}2 \text { pasang } \\
\text { panggilan } \\
\text { mengalami delay }\end{array}$ \\
\hline $384 \mathrm{k}$ & 315 & 36,2 & 0 & Panggilan lancar \\
\hline $512 \mathrm{k}$ & 320,3 & 32 & 0 & Panggilan lancar \\
\hline $\begin{array}{c}\text { rata - } \\
\text { rata }\end{array}$ & 282,92 & 124,52 & 0,00 & \\
\hline
\end{tabular}

Pada Tabel 2 menunjukkan hasil data dari melakukan panggilan menggunakan simple queue dengan 2 pasang, nilai tertinggi dari bandwidth adalah $320,3 \mathrm{kbps}$ pada max limit $512 \mathrm{k}$, nilai terendah $180 \mathrm{kbps}$ pada max limit $64 \mathrm{k}$, nilai tertinggi jitter adalah $278,79 \mathrm{~ms}$ pada max limit $64 \mathrm{k}$ dan terendah $32 \mathrm{~ms}$ pada max limit $512 \mathrm{k}$.

TABEL III HASIL DATA DARI MELAKUKAN PANGGILAN MENGGUNAKAN SIMPLE QUEUE DENGAN 3 PASANG

Pada Tabel 3 menunjukkan hasil data dari melakukan panggilan menggunakan simple queue dengan 3 pasang, nilai tertinggi dari bandwidth adalah $483,5 \mathrm{kbps}$ pada max limit $512 \mathrm{k}$, nilai terendah $193,2 \mathrm{kbps}$ pada max limit $64 \mathrm{k}$, nilai tertinggi jitter adalah $305,6 \mathrm{~ms}$ pada max limit $64 \mathrm{k}$ dan terendah $12,3 \mathrm{~ms}$ pada max limit $512 \mathrm{k}$

\section{B. Hasil tabel dari queue tree}

TABEL IV

HASIL DATA DARI MELAKUKAN PANGGILAN MENGGUNAKAN QUEUE TREE DENGAN 1 PASANG.

\begin{tabular}{|c|c|c|c|c|}
\hline \multirow{2}{*}{$\begin{array}{c}\text { Max } \\
\text { limit } \\
\text { pada } \\
\text { Mikrotik }\end{array}$} & \multicolumn{3}{|c|}{$\begin{array}{l}\text { Call statistik di softphone pada } \\
\text { pengujian } 1 \text { pasang }\end{array}$} & \multirow[t]{2}{*}{ Keterangan } \\
\hline & $\begin{array}{l}\text { Bandwidth } \\
\text { (kbps) }\end{array}$ & $\begin{array}{l}\text { Jitter } \\
(\mathrm{ms})\end{array}$ & $\begin{array}{l}\text { Packet } \\
\text { loss } \\
(\%) \\
\end{array}$ & \\
\hline $64 \mathrm{k}$ & 120,7 & 317,98 & 0 & $\begin{array}{c}\text { Panggilan putus } \\
\text { putus suara tidak } \\
\text { jelas, dikarenakan } \\
\text { jitter besar dan tidak } \\
\text { ada packet loss }\end{array}$ \\
\hline $128 \mathrm{k}$ & 159,2 & 104,55 & 0 & $\begin{array}{c}\text { Panggilan ada delay } \\
\text { tetapi jitternya tidak } \\
\text { sebesar max limit } \\
64 \mathrm{k} \\
\end{array}$ \\
\hline $256 \mathrm{k}$ & 155,6 & 31,15 & 0 & Panggilan lancar \\
\hline $512 \mathrm{k}$ & 156,5 & 12,3 & 0 & Panggilan lancar \\
\hline rata -rata & 148 & 116,49 & 0,00 & \\
\hline
\end{tabular}

Pada table 4.4 menunjukkan hasil data dari melakukan panggilan menggunakan queue tree menggunakan 1 pasang, nilai tertinggi dari bandwidth adalah $159,2 \mathrm{kbps}$ pada max limit $128 \mathrm{k}$, nilai terendah $120,7 \mathrm{kbps}$ pada max limit $64 \mathrm{k}$. nilai tertinggi jitter adalah $317,98 \mathrm{~ms}$ pada max limit $64 \mathrm{k}$ dan terendah $12,3 \mathrm{~ms}$ pada max limit $512 \mathrm{k}$.

TABEL V

HASIL DATA DARI MELAKUKAN PANGGILAN MENGGUNAKAN QUEUE TREE DENGAN 2 PASANG

\begin{tabular}{|c|c|c|c|c|}
\hline \multirow{2}{*}{$\begin{array}{c}\text { Max } \\
\text { limit } \\
\text { pada } \\
\text { Mikrotik }\end{array}$} & \multicolumn{2}{|c|}{$\begin{array}{c}\text { Call statistik di softphone pada } \\
\text { pengujian 2 pasang }\end{array}$} & \multirow{2}{*}{ Keterangan } \\
\cline { 2 - 4 } & $\begin{array}{c}\text { Bandwidth } \\
\text { (kbps) }\end{array}$ & $\begin{array}{c}\text { Jitter } \\
(\mathrm{ms})\end{array}$ & $\begin{array}{c}\text { Packet } \\
\text { loss } \\
(\%)\end{array}$ & \\
\hline $64 \mathrm{k}$ & 172,5 & 272,6 & 0 & $\begin{array}{c}\text { Panggilan putus, } \\
\text { dikarenakan } \\
\text { bandwidth yang } \\
\text { terlalu kecil. }\end{array}$ \\
\hline $128 \mathrm{k}$ & 281,2 & 133,77 & 0 & $\begin{array}{c}\text { Panggilan pada 1 } \\
\text { pasang putus, } \\
\text { dan 1 pasangnya } \\
\text { lagi delay }\end{array}$ \\
\hline $256 \mathrm{k}$ & 314,5 & 95,7 & 0 & $\begin{array}{c}\text { 2 pasang } \\
\text { panggilan } \\
\text { mengalami delay }\end{array}$ \\
\hline $512 \mathrm{k}$ & 320,3 & 2,21 & 0 & Panggilan lancar \\
\hline rata -rata & 272,125 & 126,05 & 0,00 & \\
\hline
\end{tabular}

Pada table 5 menunjukkan hasil data dari melakukan panggilan menggunakan queue tree menggunakan 2 pasang, 
Jurnal Jaringan Telekomunikasi (Jurnal Jartel) E-ISSN:2654-6531 P-ISSN: 2407-0807 Vol. 10, No.4 (2020) 185-190

nilai tertinggi dari bandwidth adalah $320,3 \mathrm{kbps}$ pada $\max$ limit $512 \mathrm{k}$, nilai terendah $172,5 \mathrm{kbps}$ pada max limit $64 \mathrm{k}$, nilai tertinggi jitter adalah $272,6 \mathrm{~ms}$ pada max limit $64 \mathrm{k}$ dan terendah $2,21 \mathrm{~ms}$ pada max limit $512 \mathrm{k}$ TABEL VI

HASIL DATA DARI MELAKUKAN PANGGILAN MENGGUNAKAN QUEUE TREE DENGAN 3 PASANG

\begin{tabular}{|c|c|c|c|c|}
\hline \multirow{2}{*}{$\begin{array}{c}\text { Max } \\
\text { limit } \\
\text { pada } \\
\text { Mikrotik }\end{array}$} & \multicolumn{2}{|c|}{$\begin{array}{c}\text { Call statistik di softphone pada } \\
\text { pengujian 3 Pasang }\end{array}$} & \multirow{2}{*}{ Keterangan } \\
\cline { 2 - 4 } & $\begin{array}{c}\text { Bandwidth } \\
(\mathrm{kbps})\end{array}$ & $\begin{array}{c}\text { Jitter } \\
(\mathrm{ms})\end{array}$ & $\begin{array}{c}\text { Packet loss } \\
(\%)\end{array}$ & \\
\hline $64 \mathrm{k}$ & 207 & 272,6 & 0 & $\begin{array}{c}\text { Panggilan } \\
\text { putus, } \\
\text { dikarenakan } \\
\text { jitter yang besar }\end{array}$ \\
\hline $128 \mathrm{k}$ & 381 & 237,79 & 0 & $\begin{array}{c}\text { Panggilan putus } \\
\text { dikarenakan } \\
\text { jitter yang besar }\end{array}$ \\
\hline $256 \mathrm{k}$ & 476,3 & 144,55 & 0 & $\begin{array}{c}\text { Panggilan tidak } \\
\text { terputus tetapi } \\
\text { delay }\end{array}$ \\
\hline $512 \mathrm{k}$ & 472,9 & 14,55 & 0 & $\begin{array}{c}\text { Panggilan } \\
\text { lancar }\end{array}$ \\
\hline $\begin{array}{c}\text { rata - } \\
\text { rata }\end{array}$ & 384,3 & 167,37 & 0,00 & \\
\hline
\end{tabular}

Pada table 6 menunjukkan hasil data dari melakukan panggilan menggunakan queue tree menggunakan 3 pasang, nilai tertinggi dari bandwidth adalah $476,3 \mathrm{kbps}$ pada max limit $256 \mathrm{k}$, nilai terendah $207 \mathrm{kbps}$ pada max limit $64 \mathrm{k}$, nilai tertinggi jitter adalah $272,6 \mathrm{~ms}$ pada max limit $64 \mathrm{k}$ dan terendah $14,55 \mathrm{~ms}$ pada max limit $512 \mathrm{k}$

\section{KESIMPULAN}

Manejemen bandwidth menggunakan simple queue dan queue tree pada routerboard RB951 sangat mempengaruhi koneksi upload dan download maka penggunaan dibagi sesuai dengan kebutuhan client agar lebih efisian koneksi penggunaan internetnya dan lebih merata. Dengan winbox versi 3.21 konfigurasi dengan mikrotik routerboard RB951 bisa kompatibel dan sesuai yang diharapkan untuk proses konfigurasi ini. Semakin kecil nilai pada max limit, maka nilai jitter akan semakin besar. Pada saat nilai jitter besar maka panggilan akan mengalami putus-putus atau mati. Semakin besar nilai pada max limit, maka nilai jitter akan semakin kecil. Pada saat nilai jitter kecil maka panggilan akan lancar.

\section{REFERENSI}

[1] []. "Management Bandwidth Internet," pp. 1-7, 2004.

[2] F. Arwani, "Sistem Manajemen Bandwidth pada Jaringan Komunikasi Voice Over Internet ( VoIP ) dengan Metode Load Balancing," J. Mhs. TEUB, vol. 3, no. 2, pp. 2-3, 2015.

[3] W. Y. Bagas Prawira Adji Wisesa, Aswin Suharsono, "Analisis Perbandingan Sistem Manajemen Bandwidth Berbasis Class-Based Queue Dan Hierarchical Token Bucket Untuk
Jaringan Komputer," J. Pengemb. Teknol. Inf. dan Ilmu Komput., vol. 2, no. 6, pp. 2067-2074, 2018.

[4] C. A. Pamungkas, "Manajemen bandwith menggunakan mikrotik routerboard di politeknik indonusa surakarta," Inf. Politek. Indonusa Surakarta, vol. 1, pp. 3-8, 2016.

[5] E. Darmawan, I. Purnama, T. Ihromi, R. Mahardika, and I. W. S. Wicaksana, "Bandwidth Manajemen Queue Tree VS Simple Queue," Konf. Nas. Sist. Inf., pp. 642-647, 2012.

[6] T. Rohman, E. K. Nurnawati, and E. Susanti, "Analisis, Perancangan Dan Implementasi Manajemen Bandwidth Menggunakan Queue Tree Pada Hotspot Mikrotik Di Wisma Muslim," J. JARKOM, vol. 7, no. 1, pp. 60-64, 2019.

[7] A. I. Wijaya and L. B. Handoko, "Manajemen Bandwidth Dengan Metode Htb ( Hierarchical Token Bucket ) Pada Sekolah Menengah Pertama Negeri 5 Semarang," J. Tek. Inform. Udinus, vol. 1, no. 1, pp. 5-7, 2015.

[8] R. Pi, "Raspberry Pi ® 199,” p. 6410, 1976.

[9] N. Hidayah, "Analisis Perbandingan Qos (Quality of Service) pada Metode Simple Queue Dan Metode Queue Tree ( studi kasus : Ancora Group )."

[10] ETSI, "Tr 101329 V2.1.1 (1999-06)," Telecommun. Internet Protoc. Harmon. Over Networks, vol. 1, pp. 1-37, 1999, [Online]. Available: http://www.etsi.org/deliver/etsi_tr/101300_101399/ 101329/02.01.01_60/tr_101329v020101p.p̄df. 